\title{
Association between helicobacter pylori infection and hyperemesis gravidarum
}

\author{
M. Elmahdy ${ }^{*}$, A. Elmarsafawy ${ }^{1}$, D. Elkafash ${ }^{2}$
}

\begin{abstract}
${ }^{1}$ Department of Obstetrics and Gynaecology, ${ }^{2}$ Department of Clinical and Chemical Pathology, Faculty of Medicine, Alexandria University, Egypt
\end{abstract}

Received: 20 July 2016

Accepted: 13 August 2016

\section{*Correspondence:}

Dr. M. Elmahdy,

E-mail: mahdy_moh@yahoo.com

Copyright: () the author(s), publisher and licensee Medip Academy. This is an open-access article distributed under the terms of the Creative Commons Attribution Non-Commercial License, which permits unrestricted non-commercial use, distribution, and reproduction in any medium, provided the original work is properly cited.

\section{ABSTRACT}

Background: Hyperemesis gravidarum is one of the serious problem affecting pregnant females. The main etiology is still unknown. Different theories were assumed. The objective of this study was to study the relationship between Helicobacter pylori infection and hyperemesis gravidarum.

Methods: case control study of 80 cases (40 case of HEG) and (40 case of normal pregnant females. assessment of helicobacter pylori antibodies in serum and stool were done for both groups.

Results: Helicobacter pylori in stool samples were positive in $75 \%$ of cases of HEG and positive in $37.50 \%$ of normal pregnant females. These results were statistically significant $(\mathrm{p}=0.001)$. The prevalence of $\mathrm{Hp} \operatorname{IgG} \mathrm{AB}$ and $\mathrm{HpSAB}$ was $77.5 \%$ in the patients with HEG, and $55.0 \%$ in controls $(\mathrm{P}=0.05)$.

Conclusions: helicobacter pylori infection may be one of the risk factors for HEG. The prevalence of helicobacter pylori $\mathrm{AB}$ in both serum and stool is more in HEG cases than in normal pregnant females.

Keywords: HEG, H. pylori, Pregnancy

\section{INTRODUCTION}

Nausea and vomiting with pregnancy is a condition that affects half of the pregnant women. Such condition usually begins between the fourth and seventh week after the last menstrual period in 80 percent of pregnant women. ${ }^{1}$

Hyperemesis gravidarum (HG) is a complication of pregnancy characterized by intractable nausea, vomiting, and dehydration and is estimated to affect $0.5-2.0 \%$ of pregnant women. ${ }^{2,3}$ Hyperemesis gravidarum tends to occur in the first trimester of pregnancy. ${ }^{4}$ When hyperemesis gravidarum is severe or inadequately treated, it may result in the following: loss of $5 \%$ or more of pre-pregnancy body weight. $^{2}$ Dehydration, causing ketosis, metabolic imbalances such as metabolic ketoacidosis or thyrotoxicosis. $2,4,5$
Helicobacter pylori, previously Campylobacter pylori, is a Gram-negative, microaerophilic bacterium found in the stomach, and may be present in other parts of the body, such as the eye. ${ }^{6,7}$

Nashaat et al suggested that chronic infection with Helicobacter pylori may a role in hyperemesis gravidarum. ${ }^{8}$ However; other studies were not able to demonstrate correlation between seropositivity for Helicobacter pylori and time of onset or duration of hyperemesis. ${ }^{9}$

The purpose of this study is to investigate the possible association between Helicobacter pylori infection and hyperemesis gravidarum in a group of pregnant women in first trimester. 


\section{METHODS}

This study has been approved by national research ethics committee and has been performed in accordance with the ethical standards as laid down in the 1964 declaration of Helsinki and its later amendments or comparable ethical standards.

Informed consent was obtained from all individual participants included in the study.

This study is a case control study carried out on 80 pregnant females attending the antenatal care clinic of El Shatby Maternity University Hospital in the period from April 2015 till March 2016. They were divided into two groups.

Forty (50\%) pregnant females complaining of hyperemesis gravidarum (cases) and forty (50\%) normal pregnant females (controls) were enrolled in the study.

\section{Inclusion criteria}

Cases were pregnant females between 5 to 15 weeks of gestation and met the following criteria for hyperemesis gravidarum: severe vomiting (more than 3 times a day), weight loss (more than 5\% of body weight), and ketonuria. 40 pregnant women were with the same gestational age but without symptoms of nausea and vomiting were involved the study as control group. Both groups were comparable for age, parity, and ultrasonographical age.

\section{Exclusion criteria}

Patients with known thyroid disease, multiple gestations, and gestational trophoblastic disease, psychological and gastrointestinal disorders were excluded.

Demographic data of both groups were recorded. Gestational age was determined using the first date of last menstrual period and confirmed by ultrasonography. The participants eligible for the study had been informed about the study before blood samples and stool specimens were collected.

\section{Determination of $\mathrm{H}$ pylori IgG antibody}

Samples were obtained by venipuncture and centrifuged at $3000 \mathrm{rpm}$ for 10 minutes. Serum specimens were stored at $-30^{\circ} \mathrm{C}$ until analysis. $\mathrm{H}$ pylori $\operatorname{IgG}$ antibody ( $\mathrm{HpIgG} \mathrm{Ab}$ ) was measured using enzyme-linked immunosorbent assay (ELISA) kits. Results were evaluated by BioTek ELx 800 ELISA reader. Test results were reported as positive, negative, and equivocal. The threshold value for a "positive" result was accepted as $\geq$ 1.00 and $\leq 0.9$ as a negative result. Values between0 .910.99 were interpreted as equivocal.

\section{Determination of $\mathrm{H}$ pylori stool antigen}

Stool samples from each patient were collected into clean cups and stored at $-30^{\circ} \mathrm{C}$ until analysis. All samples were tested for $\mathrm{H}$ pylori stool antigen ( $\mathrm{HpSA}$ ) using $\mathrm{HpSA}$ enzyme-linked immunosorbent assay (Diagnostic BioProbes srl, Milano, Italy) according to the manufacturer's instructions. The cutoff value for a positive result was considered as $\geq .298$ at optical density of $450 \mathrm{~nm}$ and $<.298$ as a negative result.

\section{Statistical analysis of the data}

Data were fed to the computer and analyzed using IBM SPSS software package version 20.0. Qualitative data were described using number and percent. Quantitative data were described using range (minimum and maximum), mean, standard deviation and median. Significance of the obtained results was judged at the $5 \%$ level

\section{The used tests were}

\section{Chi-square test}

For categorical variables, to compare between different groups

\section{Monte Carlo correction}

Correction for chi-square when more than $20 \%$ of the cells have expected count less than 5

\section{Student t-test}

For normally quantitative variables, to compare between two studied groups

\section{Z for Mann Whitney test}

For abnormally quantitative variables, to compare between two studied groups.

\section{RESULTS}

Forty $(50 \%)$ pregnant females complaining of hyperemesis gravidarum (cases) and forty (50\%) normal pregnant females (controls) were enrolled in the study during the period from April 2015 till March 2016. There was no cancelled or dropped cases from the study.

The ages of the women in both groups ranged from 20 to 35 years, they were more or less matched for age; the mean age of patients was $27.50 \pm 4.66$ while that of the controls was $26.95 \pm 4.71$ (Table 1 ).

Body weight was significantly lower among patients as compared to controls (Table 1). 
Table 1: Comparison between the two groups according to demographic data.

\begin{tabular}{|c|c|c|c|c|}
\hline & Cases $(n=40)$ & Control $(n=40)$ & $\mathrm{T}$ & $\mathbf{P}$ \\
\hline \multicolumn{5}{|l|}{ Age (years) } \\
\hline Min. - max. & $20.0-35.0$ & $20.0-35.0$ & \multirow{3}{*}{0.525} & \multirow{3}{*}{0.601} \\
\hline Mean \pm SD & $27.50 \pm 4.66$ & $26.95 \pm 4.71$ & & \\
\hline Median & 27.50 & 26.50 & & \\
\hline \multicolumn{5}{|l|}{ Weight (kg) } \\
\hline Min. - max. & $42.0-74.0$ & $57.0-83.0$ & \multirow{3}{*}{$5.461 *$} & \multirow{3}{*}{$<0.001 *$} \\
\hline Mean \pm SD & $60.40 \pm 10.45$ & $71.70 \pm 7.88$ & & \\
\hline Median & 59.50 & 73.50 & & \\
\hline
\end{tabular}

$\mathrm{t}$ : Student $\mathrm{t}$-test; *: Statistically significant at $\mathrm{p} \leq 0.05$.

Table 2: Comparison between the two groups according to obstetric history.

\begin{tabular}{|c|c|c|c|c|}
\hline & Cases $(n=40)$ & Control $(n=40)$ & Test of sig. & $\mathbf{P}$ \\
\hline \multicolumn{5}{|l|}{ Gravidity } \\
\hline Min. - max. & $1.0-6.0$ & $1.0-6.0$ & \multirow{3}{*}{$Z=0.829$} & \multirow{3}{*}{0.407} \\
\hline Mean \pm SD & $2.45 \pm 1.36$ & $2.25 \pm 1.39$ & & \\
\hline Median & 2.0 & 2.0 & & \\
\hline \multicolumn{5}{|l|}{ Parity } \\
\hline Min. - max. & $0.0-5.0$ & $0.0-5.0$ & \multirow{3}{*}{$Z=0.618$} & \\
\hline Mean \pm SD & $1.25 \pm 1.21$ & $1.10 \pm 1.19$ & & \multirow{2}{*}{0.537} \\
\hline Median & 1.0 & 1.0 & & \\
\hline \multicolumn{5}{|l|}{ Abortion } \\
\hline Min. - max. & $0.0-2.0$ & $0.0-2.0$ & \multirow{3}{*}{$Z=0.306$} & \multirow{3}{*}{0.760} \\
\hline Mean \pm SD & $0.20 \pm 0.52$ & $0.18 \pm 0.50$ & & \\
\hline Median & 0.0 & 0.0 & & \\
\hline
\end{tabular}

Z: Z for Mann Whitney test.

Table 3: Comparison between the two groups according to vital signs.

\begin{tabular}{|c|c|c|c|c|}
\hline & Cases $(n=40)$ & Control $(n=40)$ & $\mathbf{T}$ & $\mathbf{P}$ \\
\hline \multicolumn{5}{|l|}{ Systolic } \\
\hline Min.- max. & $80.0-100.0$ & $100.0-130.0$ & \multirow{3}{*}{$13.933 *$} & \multirow{3}{*}{$<0.001 *$} \\
\hline Mean \pm SD & $89.13 \pm 6.97$ & $116.0 \pm 10.01$ & & \\
\hline Median & 90.0 & 117.50 & & \\
\hline \multicolumn{5}{|l|}{ Diastolic } \\
\hline Min.-max. & $50.0-75.0$ & $70.0-80.0$ & \multirow{3}{*}{$9.985 *$} & \multirow{3}{*}{$<0.001 *$} \\
\hline Mean \pm SD & $60.75 \pm 7.81$ & $75.0 \pm 4.53$ & & \\
\hline Median & 60.0 & 75.0 & & \\
\hline \multicolumn{5}{|l|}{ Pulse } \\
\hline Min. - max. & $75.0-96.0$ & $71.0-84.0$ & \multirow{3}{*}{$7.862 *$} & \multirow{3}{*}{$<0.001^{*}$} \\
\hline Mean \pm SD & $86.45 \pm 7.32$ & $76.52 \pm 3.19$ & & \\
\hline Median & 87.50 & 76.0 & & \\
\hline
\end{tabular}

t: Student t-test; *: Statistically significant at $\mathrm{p} \leq 0.05$.

There was no significant difference between patients and controls according to obstetric history (Table 2).

A significant difference between patient and controls according to vital signs including systolic blood pressure, diastolic blood pressure, and pulse rate (Table 3).
H. pylori stool antigen (HpSA) was $77.5 \%$ (31 of 40) in the patients with HEG, and $55.0 \%$ (22 of 40) in controls $(\mathrm{P}=0.05 ; \chi 2=4.528)$. These results are considered as significant one (Figure 1).

Helicobacter pylori in stool samples were 30 positive of 40 cases with $75 \%$ and 15 positive of 40 controls with 
$37.50 \%$. These results were statistically significant difference $(\mathrm{p}=0.001)$ (Figure 2).
Regarding the prevalence of H. Pylori, it didn't differ with age, gravidity and parity in cases group (Table 4).

Table 4: Relation between helicobacter pylori with age, gravidity and parity in cases group.

\begin{tabular}{|c|c|c|c|c|}
\hline & \multicolumn{2}{|c|}{ Helicobacter pylori } & \multirow{2}{*}{ Test of sig. } & \multirow{2}{*}{$\mathbf{P}$} \\
\hline & Negative $(n=9)$ & Positive $(n=31)$ & & \\
\hline \multicolumn{5}{|l|}{ Age (years) } \\
\hline Min. - max. & $21.0-32.0$ & $20.0-35.0$ & \multirow{3}{*}{$\mathrm{t}=0.201$} & \multirow{3}{*}{0.842} \\
\hline Mean \pm SD & $27.22 \pm 3.70$ & $27.58 \pm 4.95$ & & \\
\hline Median & 27.0 & 28.0 & & \\
\hline \multicolumn{5}{|l|}{ Gravidity } \\
\hline Min. - max. & $1.0-3.0$ & $1.0-6.0$ & \multirow{3}{*}{$Z=1.306$} & \multirow{3}{*}{0.192} \\
\hline Mean \pm SD & $1.89 \pm 0.78$ & $2.61 \pm 1.45$ & & \\
\hline Median & 2.0 & 3.0 & & \\
\hline \multicolumn{5}{|l|}{ Parity } \\
\hline Min. - max. & $0.0-2.0$ & $0.0-5.0$ & \multirow{3}{*}{$Z=0.826$} & \multirow{3}{*}{0.409} \\
\hline Mean \pm SD & $0.89 \pm 0.78$ & $1.35 \pm 1.31$ & & \\
\hline Median & 1.0 & 1.0 & & \\
\hline
\end{tabular}

$\mathrm{Z}$ : Z for Mann Whitney test; $\mathrm{t}$ : Student t-test.

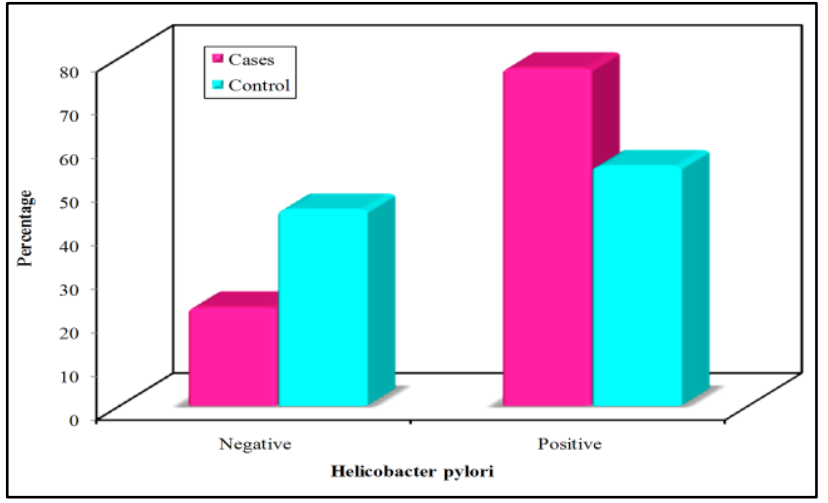

Figure 1: Distribution between the two groups according to helicobacter pylori seropositivity.

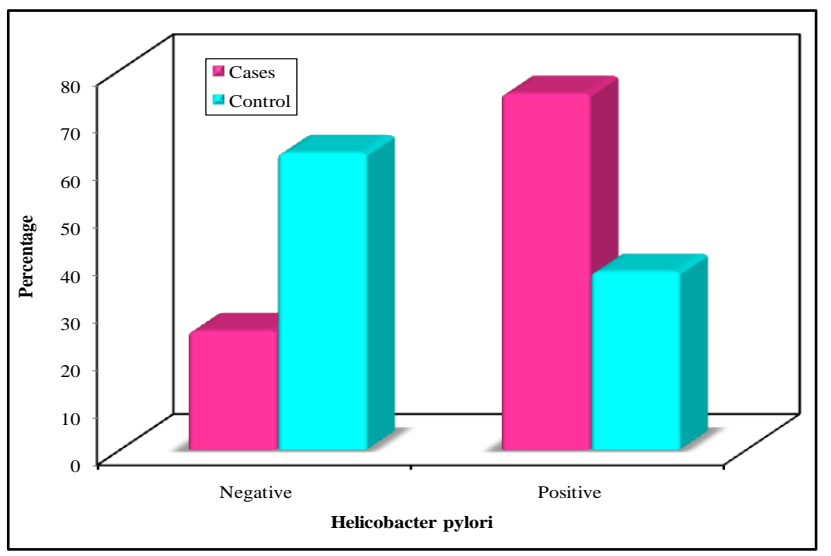

Figure 2: Distribution between the two groups according to helicobacter pylori testing in stool samples.

\section{DISCUSSION}

Vomiting is a common condition affecting about $50 \%$ of pregnant women, with another $25 \%$ suffering from nausea. ${ }^{10}$ However, the incidence of HEG is only 0.3$1.5 \% .^{11}$ Its cause is theoretical, Helicobacter pylori $(\mathrm{H}$. pylori) is considered one of its reasons. H. pylori was first discovered in the stomachs of patients with gastritis and ulcers in 1982. ${ }^{12} \mathrm{H}$. pylori is a helix-shaped (classified as a curved rod, not spirochaete) gram-negative microaerophilic bacterium. ${ }^{13}$

This study was conducted to analyses the relation between $\mathrm{H}$. pylori infection and HEG.

There was a significantly higher rate of $\mathrm{H}$. pylori seropositivity among hyperemetic patients $(77.5 \%)$ compared to controls $(55.0 \%), \mathrm{p}=0.058$.

Frigo et al reported that $90.5 \%$ of women with HG were seropositive for $\mathrm{H}$. pylori as compared to $46.5 \%$ of controls. ${ }^{14}$ Another study from Turkey with hyperemesis gravidarum (HG) found that $92 \%$ were seropositive for H. pylori (HP) as compared to $45 \%$ of controls. ${ }^{15}$ Although these two European studies strongly suggested that HEG may be associated with $\mathrm{H}$. pylori infection, other two studies found no association between HG and H. pylori seropositivity, one conducted in two US populations with disparate $H$. pylori seropositivity and the other by Berker et al from Turkey. ${ }^{16,17}$ Rafie $\mathrm{S}$ et al found no association between HEG and H.Pylori infection. ${ }^{18}$ Golberg D et al and Irene Sandven et al reported an association between hyperemesis gravidarum and $\mathrm{H}$ pylori infection. ${ }^{19,20}$ 
Salimi et al found that positive serum H. pylori IgG antibody was detected in $88.9 \%$ of the patients in the experimental group versus $40.7 \%$ of the controls $(\mathrm{P}<0.001)$. Although more patients with $\mathrm{HG}$ were seropositive for $\mathrm{H}$. pylori infection than controls, they were not able to demonstrate correlation between seropositivity for $\mathrm{H}$. pylori and the time of onset or duration of HG symptoms. Although H. pylori infection may be an important factor in exacerbating $\mathrm{HG}$, it may not represent the sole cause of the disease. ${ }^{21}$

On the other hand Vikanes et al did not find H. pylori exposure to be significantly associated with severe HG among immigrant women in Norway. This was either when $H$. pylori exposure was investigated by $\operatorname{IgG}$ seropositivity, CagA and VacA seropositivity or by the presence of $\mathrm{H}$. pylori antigens in stool. These results may show that the association between $\mathrm{H}$. pylori and $\mathrm{HG}$ is weaker than previously expected, particularly in populations with high prevalence of $\mathrm{H}$. pylori infection. ${ }^{22}$

Our results and the results found in previous studies showed that there is an association between HEG and H. Pylori infection. H. pylori infection is one of the causes of GIT disturbance and nausea and vomiting in general population. But, H. Pylori infection detected by the seropositivity for its antibodies is also, prevalent in asymptomatic population as found by Sarker et al. They found the high seroprevalence of cagA- and vacApositive virulent $H$. pylori strains in an asymptomatic paediatric population indicate that such strains are common in this population and may cause characteristic H. pylori infection in Bangladesh. ${ }^{23}$ So, geographical distribution, age, general condition of the female and patient susceptibility may be confounding factors for the association of $\mathrm{H}$. pylori infection with sever HEG cases.

\section{CONCLUSION}

Severe form of HEG is associated with $H$. pylori infection. H. pylori infection may be listed as one of the risk factors for sever HEG.

\section{ACKNOWLEDGEMENTS}

To clinical pathology laboratory team due to their assistance.

Funding: No funding sources Conflict of interest: None declared

Ethical approval: The study was approved by the Institutional Ethics Committee

\section{REFERENCES}

1. Niebyl JR. Nausea and vomiting in pregnancy. N Engl J Med. 2010;363:1544-50.

2. Summers A. Emergency management of hyperemesis gravidarum. Emergency nurse. 2012;20(4):24-8.
3. Goodwin TM. Hyperemesis gravidarum. Obstetrics and gynecology clinics of North America. 2008;35(3):401-17.

4. Ahmed KT, Almashhrawi AA, Rahman RN, Hammoud GM, Ibdah JA. Liver diseases in pregnancy: diseases unique to pregnancy. World J Gastroenterol. 2013;19(43):7639-46.

5. Matthews DC, Syed AA. The role of TSH receptor antibodies in the management of Graves' disease. European journal of internal medicine. 2011;22(3):213-6.

6. Giusti C. Association of helicobacter pylori with central serous chorioretinopathy: hypotheses regarding pathogenesis. Medical Hypotheses. 2004;63(3):524-7.

7. Ahnoux-Zabsonre A, Quaranta M, Mauget-Faÿsse M. Prévalence de l'Helicobacter pylori dans la choriorétinopathie séreuse centrale et l'épithéliopathie rétinienne diffuse prevalence of helicobacter pylori in central serous chorioretinopathy and diffuse retinal epitheliopathy: a complementary study. Journal Français d'Ophtalmologie (in French). 2004;27(10):1129-33.

8. Nashaat EH, Mansour GM. Helicobacter pylori and Hyperemesis Gravidarum Continuous Study. Nature Sci. 2010;8(7):22-6.

9. Sandven I, Abdelnoor M, Nesheim BI, Melby KK. Helicobacter pylori infection and hyperemesis gravidarum: a systemic review and meta -analysis of case-control studies. Acta Obstet Gynecol Scand. 2009;88:1190-200.

10. Niebyl, Jennifer R. Nausea and vomiting in pregnancy. New England Journal of Medicine. 2010;363(16):1544-50.

11. Sheehan P. Hyperemesis gravidarum--assessment and management (PDF). Australian Family Physician. 2007;36(9):698-701.

12. The Nobel Prize in Physiology or Medicine 2005. Retrieved 2 August 2008. Available at https://www.nobelprize.org/nobel_prizes/medicine/la ureates $/ 2005 /$.

13. Olson JW, Maier RJ. Molecular hydrogen as an energy source for Helicobacter pylori. Science. 2002;298(5599):1788-90.

14. Frigo P, Lang C, Reisenberger K, Kolbl H, Hirschl AM. Hyperemesis gravidarum associated with Helicobacter pylori seropositivity. Obstetrics and Gynecology. 1998;91(4):615-7.

15. Koçak I, Akcan Y, Üstün C, Demirel C, Cengiz L, Yanik FF. Helicobacter pylori seropositivity in patients with hyperemesis gravidarum. International Journal of Gynecology and Obstetrics. 1999;66(3):251-4.

16. Jacobson GF, Autry AM, Somer-Shely TL, Pieper KL, Kirby RS. Helicobacter pylori seropositivity and hyperemesis gravidarum. The Journal of Reproductive Medicine. 2003;48(8):578-82.

17. Berker B, Soylemez F, Cengiz SD, Kose SK. Serologic assay of helicobacter pylori infection. Is it 
useful in hyperemesis gravidarum? The Journal of Reproductive Medicine. 2003;48(10):809-12.

18. Tari SR. Hyperemesis gravidarum. Obstet Gynecol. Tehran Univ Med J (Tum). 2015;73(3):182-91.

19. Golberg D. Hyperemesis gravidarum and helicobacter pylori infection: a systemic review. Obstet Gynecol. 2007;110(3):695-703.

20. Sandven I. Hyperemesis gravidarum and helicobacter pylori infection epidemiology. European Journal of Epidemiology. 2008:34(3):491-8.

21. Salimi-Khayati A, Sharami H, Mansour-Ghanaei F, Sadri S, Fallah MS. Helicobacter pylori aeropositivity and the incidence of hyperemesis gravidarum. Med Sci Monit. 2003;9(1):CR12-5.

22. Vikanes AV, Støer NC, Gunnes N, Grjibovski AM, Samuelsen SO, Magnus P, et al. Helicobacter pylori infection and severe hyperemesis gravidarum among immigrant women in Norway: a case-control study. Eur J Obstet Gynecol Reprod Biol. 2013;167(1):416.

23. Sarker SA, Nahar S, Rahman M, Bardhan PK, Nair GB, Beglinger C, et al. High prevalence of cag A and vac $A$ seropositivity in asymptomatic Bangladeshi children with helicobacter pylori infection. Acta Paediatr. 2004;93(11):1432-6.

Cite this article as: Elmahdy M, Elmarsafawy A, Elkafash D. Association between helicobacter pylori infection and hyperemesis gravidarum. Int J Reprod Contracept Obstet Gynecol 2016;5:3175-80. 